\title{
Analysis of Healthcare Systems by Using Systemic Approach
}

\author{
Andrzej Bielecki $\mathbb{D}^{1}$ and Sylwia Nieszporska ${ }^{1}{ }^{2}$ \\ ${ }^{1}$ AGH University of Science and Technology, Faculty of Electrical Engineering, Automation, Computer Science and \\ Biomedical Engineering, Chair of Applied Computer Science, Poland \\ ${ }^{2}$ Częstochowa University of Technology, Faculty of Management, Chair of Statistics and Econometrics, Armii Krajowej 19B, \\ 42-200 Częstochowa, Poland \\ Correspondence should be addressed to Sylwia Nieszporska; sylniesz@poczta.onet.pl
}

Received 20 December 2018; Revised 25 March 2019; Accepted 2 April 2019; Published 21 April 2019

Guest Editor: Jose M. Gimenez-Guzman

Copyright (C) 2019 Andrzej Bielecki and Sylwia Nieszporska. This is an open access article distributed under the Creative Commons Attribution License, which permits unrestricted use, distribution, and reproduction in any medium, provided the original work is properly cited.

\begin{abstract}
National healthcare systems in all countries do not act effectively. Therefore, especially strategies for introducing organizational innovation to public organization should be considered. The problem is how to organize the research in this field. One of the generally accepted solutions is the systemic approach to healthcare systems. In this paper multiagent systems theory and autonomous systems theory are applied to the analysis of main types of healthcare systems. Such analysis allows us to consider the system properties: the level of the autonomy, energy dissipation in the system, the payoff specificity (in the meaning of game theory), functional role of the agents in the system, the level of the agents' cooperation, and delays in flows of money, requests, rules, and controls. As a result, some new functionalities of the healthcare system on the national level have been found and analysed. The aforementioned parameters are good tools to analyse the system functionality.
\end{abstract}

\section{Introduction}

Healthcare systems are more or less dysfunctional. On the one hand, contemporary medicine provides effective therapy for more and more diseases. This effectiveness is, among others, caused by high amounts of money invested into healthcare systems and medical research in developed countries. On the other hand, however, healthcare systems suffer from numerous pathologies. They can be observed on various levels such as social, managerial, medical care, and practice as well as scientific. First of all, a great number of people have very limited access to medical care that is not only in the developing world. The number of physicians per 10000 population, as one of the aspects of access to healthcare, is not very high, for example, in India (7.0), China (14.6), and Brazil (18.9). Surprisingly, the USA has not got the highest ratio (24.5), while Qatar has 77.4, Cuba 67.2, and the Russian Federation 43.1 [1]. In postcommunistic countries, especially in Poland, access to consultant doctors is very limited and the time of expectation for many kinds of medical treatments and operations is extremely long. For example, according to the Polish reports [2], expectation time for a lens transplant, because of cataract, in the public hospitals, is equal to about one year. On the other hand, there is a tendency for medical overuse which, in turn, is expensive and harmful for patients, but lucrative for healthcare providers, and can be observed in developed countries, Brenner \& Elliston [3] and Krause [4]. On the scientific level the fact that the pharmaceutical industry funnels money to prominent scientists, who are doing research that affects its products, is one of the most significant pathologies, Seife [5]. Another pathology includes increases in medical errors and lower quality care as a return on expenses, in spite of an abundance of means, Bar-Yam [6] and Krause [4]. Misinformation is another problem; usually, physicians are more likely to discuss potential benefits of the proposed treatment than potential complications and dangers, Holmboe et al. [7] and Zikmund-Fisher et al. [8].

The problems signalized above caused deep studies concerning healthcare systems as such. In particular, strategies for introducing organizational innovation to public service organizations are considered, Collm \& Schedler [9]. Intensive discussion on how the investigations should be organized 


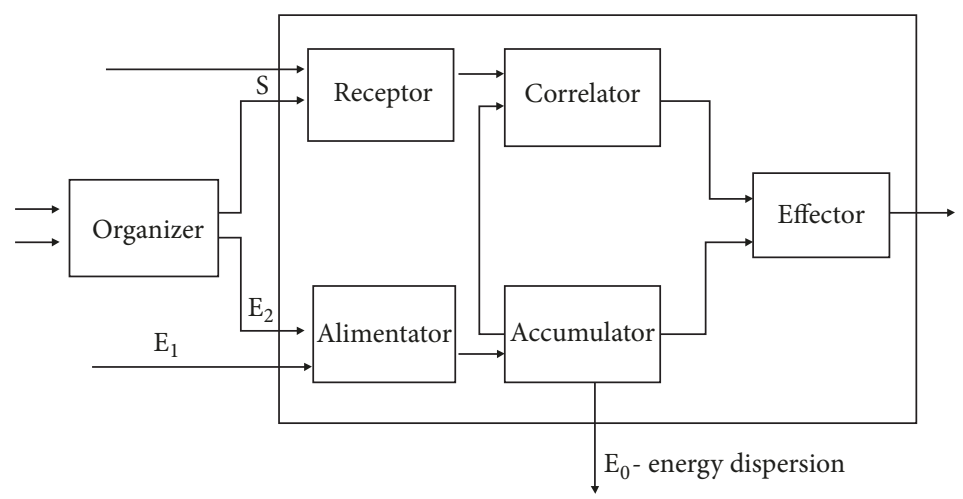

Figure 1: Cybernetic scheme of the controllable system.

in this field has started, Lenaway et al. [10]. Systems theory became one of the widely accepted methods applied to studies which concerned healthcare systems, Bielecki \& Stocki [11], Andersen [12], Mlakar \& Mulej [13], and Montgomery \& Oladapo [14]. This paper, in which a few types of healthcare systems are analyzed by using multiagent systems theory and autonomous systems, is a continuation of the analysis presented in Bielecki, \& Stocki [11]. The aim of this paper is to work out a universal method of analysis of healthcare systems on the national level, which can be applied effectively for all types of economic, political, and cultural conditions, in order to find causes of the system dysfunctions and, in turn, eliminate them effectively. Building new approach which has significant theoretical aspects is crucial for advancing the knowledge of management, Sheperd \& Suddaby [15]. Furthermore, on the basis of the proposed approach, it should be possible to work out the changes of the system in order to increase the system functionality. The proposed way is based on autonomous systems theory and multiagent systems theory. In game theory, widely applied in economics, the payoff table of the game between agents is considered. In the presented approach, relations between agents and their properties as well as the properties of the dynamics of the whole system in the context of the whole system stability and optimization are considered. The proposed approach allowed us to find some new functionalities of the healthcare system on the national level and to analyse effectively the system as a whole.

The paper is organized in the following way. In the next section formal tools, used for the healthcare systems analysis, are presented. The Mazur's autonomous systems theory is briefly recalled. The very crucial points of multiagent systems theory are presented. The game theory as well as its modifications introduced for needs of the analysis is briefly discussed as well. In the subsequent section, the proposed method of the analysis is described. Then, various types of healthcare systems are analysed. The system fully paid by the patients, the system based on insurance, the system based on health funds, the fully centralized system, and the hypothetical participative system proposed by Bielecki \& Stocki [11] are also considered. Discussion and concluding remarks are presented in the two last sections.

\section{The Formal Tools}

The Mazur's autonomous systems theory and the multiagent systems theory constitute the theoretical basis of the analysis presented in the next section. Let us present a very brief outline of the autonomous system theory of Mazur [16, 17]. The more detailed presentation of the theory in the English language can be found in Bielecki \& Stocki [11] and in Bielecki [18].

Let us recall a few definitions.

The receptor is an input module responsible for transmitting signals from the milieu.

The alimentator is an input module responsible for possessing resources from the milieu.

The effector is an output module responsible for generating reactions of the system.

The accumulator is a module responsible for storing and processing energy.

The correlator is a module responsible for generating information on the basis of the signals received from the receptor.

The homeostat is a module responsible for keeping the system in functional balance.

The structure of the system called by Mazur as a controllable system is presented in Figure 1. The system is equipped with a receptor, alimentator, accumulator, and correlator. In a controllable system, the outer organizer's role is to keep the system in functional balance and to set the goals. The outer organizer also controls the system by means of the correlator, for instance, by introducing an algorithm to the correlator.

The structure of the Mazur's autonomous system is presented in Figure 2. It is a controllable system equipped with the homeostat. The autonomous system is an organizer for itself. It is both a controlling and controlled unit which means that the autonomous system has self-controlling abilities. They are realized by ensuring functional balance in the system. The balance is kept by using a set of negative feedback loops. Such control mechanism is called homeostasis, Cannon [19]. Counteracting the factors which lead to the 


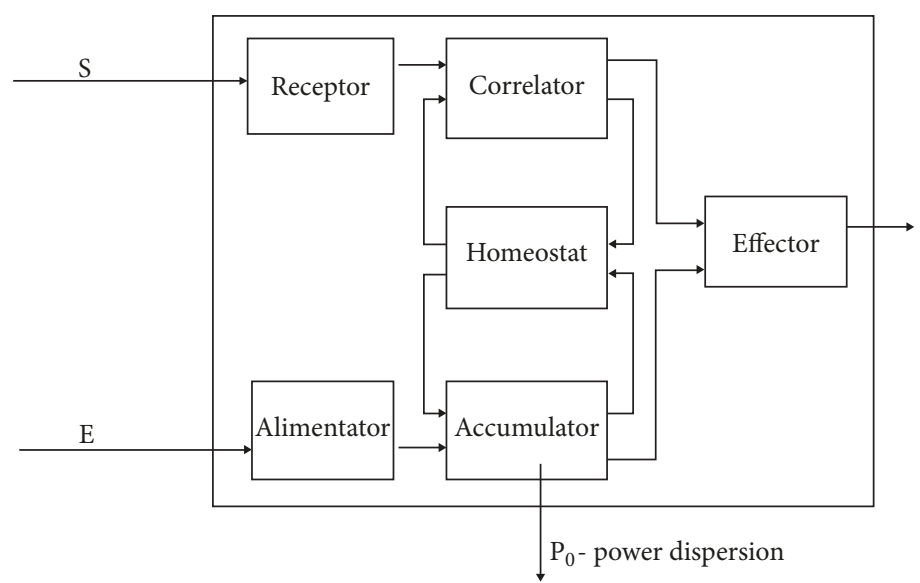

FIgURE 2: Cybernetic scheme of the autonomous system.

autonomous system disorganization is the effect of presence homeostatic control mechanisms.

As it has been aforementioned, the homeostat is the module responsible for keeping the functional balance of the system, Ashby [20]. It appears in two fundamental feedback loops in an autonomous system. The first one is the feedback loop with the accumulator, which allows controlling the energetic line, constituted by the alimentator, the accumulator, and effector. The second one is the feedback loop with the correlator, which allows controlling the information line, constituted by receptor, correlator, and effector. In the sequel of this paper, the term autonomous system is a synonymic to Mazur's autonomous systems.

Game theory, Neumann \& Morgenstern [21], Straffin [22], and Watson [23], consists in searching the optimal strategy in given conditions, i.e., such a sequence of the actions admissible for the player that maximizes his payoff. Associated with each possible outcome of a game is a collection of numerical payoffs, one to each player. These payoffs represent the value of the outcome to the different players. To sum up, there are four crucial components of the game: players, strategies, outcomes, and numerical payoffs. Game theory is the study of how the players should rationally play games. In the classical approach the only criterion is to win as large a payoff as possible, Straffin [22]. The issue which is discussed in this paper is, however, different. In the context of healthcare systems analysis, we would like to solve the following problem: for given types of the participants (agents) of the system, equipped with given properties and functionalities, find such set of rules, and such modifications of the environment to obtain the optimal whole system, i.e., the one which is maximal cooperative and stable. It should be also stressed that the stability of a game means not only resistance to external distortions in the sense of mathematical dynamical systems theory but, first of all, protection from the catastrophic finish of the whole system, i.e., such situation that the activities of the agents cannot be continued and, as a consequence, the existence of the participants is threatened. Very illustrative example can be found in biology.
If an extremely effective parasite leads its host to death then the short-term (tactical) payoff of the parasite is maximal but in the long-term (strategic) perspective the parasite, usually, will die as well because of the lack of the host. This means that the game between the parasite and its host has finished catastrophically; it has not been stable. In the economic games catastrophic finish can be caused by the ruin of the key players or by the excessive dispersion of means. The additional problem is that the nature of the environment limits its possible modifications, and both the environment and properties of the players generate limitations of possible rules. In order to solve the aforementioned problem the properties of the agents are analysed from the multiagent systems theory point of view, Ferber [24] and Sulis [25]. Each module in the healthcare system is considered as an agent which takes part in the game. The term game, however, is used here in more general meaning than in game theory. Each agent has its own aims, both local and global. It turns out that, in the healthcare system analysis, it is insufficient to limit aim descriptions only to numerical payoff. In some cases the aims have to be described qualitatively. Such description is a good starting point for the analysis of the players' aim concordance and, as a consequence, the game cooperativeness and stability. The high level of two last properties of a game results in minimal dispersion of energy in the whole systems. For the healthcare systems this means maximal effectiveness of utilization of money and all resources, like people and infrastructure, coming into the system.

\section{The Proposed Approach to the Analysis of Healthcare Systems}

Let us put forward the proposed methodology of the analysis of complex systems which consist of various types of agents interacting mutually. The following steps of the analysis should be conducted.

(1) Specification of the types of agents which act in the system in the context of their functionalities. 
(2) Analysis of the properties of the specified types of the agents. In particular, what sort of system according to Mazur's theory represents a given agent, i.e., whether it is an autonomous system, or rather fully or partially controlled, and how the agent's inner modules (correlator, accumulator, and homeostat) are organized.

(3) Analysis of the aims of the individual types of agents, both the tactical (short-term) aims and the strategic (long-term) ones.

(4) Specification of relations and interactions between agents, in particular,
(a) specification of flows of the means,
(b) specification of flows of energy,
(c) specification of services,
(d) specification of controls,
(e) specification of demands specified between agents.

The enumerated specification can be presented as a chart of flows, which is a common method used in cybernetics.

(5) Analysis of the relations and interactions specified above, among other analyses of the energy dissipation in individual flows and delay in flows, services and controls.

(6) Analysis of the whole system, among others,

(a) what sort of the system, according to Mazur's theory, is the whole system,

(b) whether there exists privileged agents in the system,

(c) whether the whole system is cooperative or not, i.e., whether individual agents cooperate or compete,

(d) payoff type of the game, i.e., if the whole system, which is considered in its dynamics as a game, is a zero-sum game or a negative-sum game,

(e) stability of the whole system, in particular, whether there exist positive feedback loops in the system, which are destroying unless they are controlled, in particular by subordination to a controlling negative feedback loop.

The specified approach allows the researcher to identify the sources of pathologies in the system and, as a consequence, to work out the way they can be removed.

\section{The Analysis of Various Types of Healthcare Systems}

The healthcare systems can be organized at the level of the state in various ways. Below, the main types of the healthcare systems are briefly recalled. The more detailed description

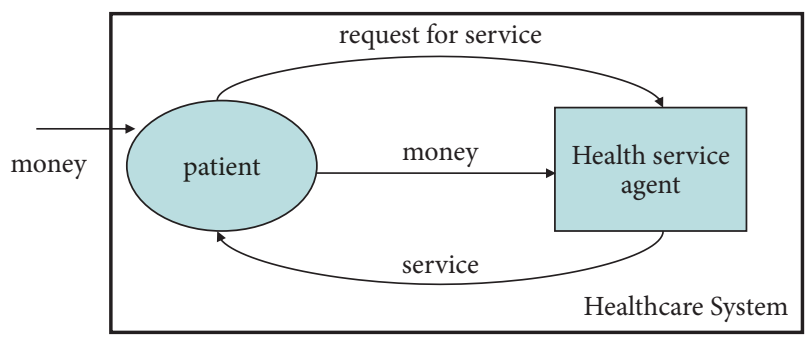

FIGURE 3: The scheme of relations between agents in a privately financed healthcare system.

of the general properties of the considered primary systems can be found in Bielecki \& Stocki [11]. In this paper their properties from the game theory point of view are analysed. Before starting the cybernetic analysis of healthcare systems, it should be stressed that energy, in cybernetics meaning, is the means that enable the system to sustain its existence and perform actions. In the healthcare system, apart from physical energy, for example, electricity and heating necessary for the hospitals functioning and money play the role of energy.

4.1. Type 1: The Residual System. In this type of healthcare systems medical services are fully and immediately paid by the patients and, in return for this, they are provided immediately, as well. In the clear primary system of this type all medical facilities are private. In the residual healthcare system medical service is simply a good, which can be bought or not, depending on the patient's own decision. Contemporary, this kind of healthcare system dominates in dentistry and veterinary. Historically, it was characteristic for most European countries in the 19th century. A scheme of flows of demands, services, and money in such system is presented in Figure 3.

Contemporary systems of veterinary services, and in most cases dental services, are organized according to this model. Two types of agents exist in this type of the healthcare system: patients, and healthcare agents, i.e., physicians and hospitals (including local clinics). The market in which the paid health service is offered is the agents' environment. This healthcare system is almost closed which means that there are neither outer influences on the system nor flows to the system apart from money earned by the patients. Furthermore, the system does not influence the other areas of social reality. Thus, the whole system is autonomous. Each agent is an autonomous system as well. The patient's accumulator contains only his private resources. This implies that the means of the patient are, in most cases, very limited and it allows him to purchase only very basic service. What is worse, during serious diseases as well as the chronic ones the patient cannot possess means. Therefore, possibilities to treat these types of diseases are limited only to the most wealthy people, which are small part of the society. Analysing this type of the system from cybernetic point of view, only three types of interactions between agents in this system can be distinguished: flow of energy (money) from patients to service agents such as physicians and hospitals, service request from patient to service agent, and flow of service 


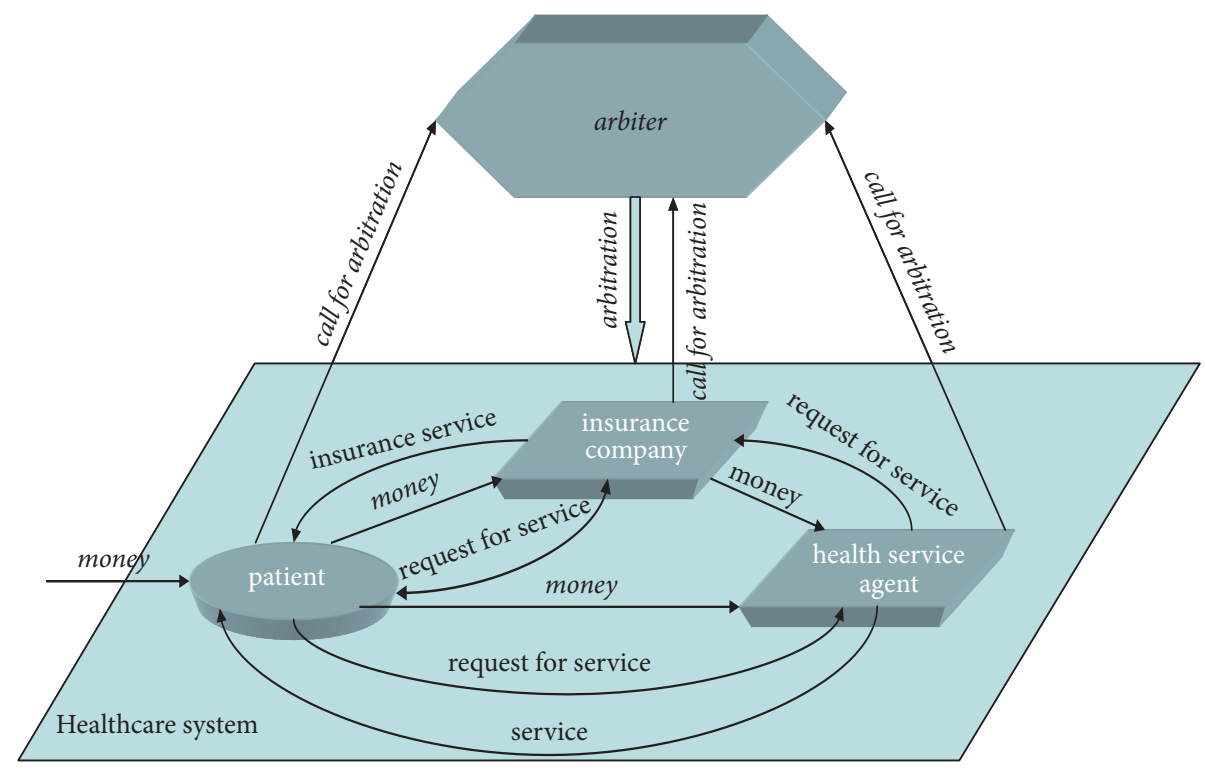

FIGURE 4: The scheme of relations between agents in the US model.

from service agents to the patients. There are no interactions between physician and hospitals. The physician employed at the hospital becomes a part of its effector and does not play a role of the separate system in the whole system of healthcare. Only the physicians that are in private practice are agents in the considered system. The game is the zerosum game whereby all money paid by the patients is the service agents' income. This is the crucial advantage of the whole system; there are no means (cybernetic energy) for dissipation. Furthermore there are no delays in flows. The qualitative goals of the patients and service agents are not fully consistent. It is true that the local (tactical) goals are partially consistent in that the patient wants to be cured and the physician wants to cure him in order to get money. On the other hand, however, the health agent wants to get as much money as possible, whereas the patient wants to pay the minimal sum of money possible for the service. Furthermore, the global goals are against each other. The patient wants to be healthy but it is not the service agents' interest because the healthy person does not need medical service. The agents have full freedom of strategic choice. On the other hand, in the market environment, optimal strategies are, in a way, forced. The patient may choose any service agent or may go to different agents at the same time. The choice depends entirely on him, whereas the service agents, which act in a market environment, try to cover the needs with their services. The whole system is not, however, fully functional. Because of the aforementioned limitation of the patients' resources, medical service is provided only to small part of the society. Therefore, the healthcare system is far from optimal usage of its potential.

\subsection{Type 2: Healthcare Costs Covered by Insurance Companies:} The US Model. This system is characteristic of the third sort of agents that are participants in the game which are the insurance companies; see Figure 4 . In this system patients buy packets of healthcare services from insurance companies. All three types of the agents, healthcare agents, patients, and insurance institutions, are autonomous systems. In the case of illness the patient draws from financial resources accumulated by the insurance company. The effectiveness of the system is based on the fact that the frequency of serious and chronic diseases is relatively low, and the costs of treatment of common diseases are relatively low.

Therefore, insurance institutions can effectively play the role of additional accumulators of the whole complex system of healthcare. This is the advantage of this system over the first model; the health services may be offered to a greater group of people than in type 1 of the healthcare system. Divergence of the goals of the insurance firms and the remaining two participants is the most important disadvantage of the system. The interest of the company is to get the highest price for their insurance and spend as little as possible on covering the treatment costs. The interest of the hospital and physicians is to secure the possibly high inflow of financial means to provide the health services. This weakness manifests, among other things, in many litigations that end up in court, the outer arbiter. The insurance companies are called to court for finding any pretext to refuse to cover the costs of treatment. On the other hand, it happens that hospitals get money out of the insurance companies for fictitious services. Oftentimes the conditions of insurance are formulated in an unclear way on purpose to make their interpretation difficult. This means that in the game there is crucial conflict of tactical (short-term) interests between insurance companies and the healthcare subsystem that consists of patients and healthcare agents. The whole system is autonomous with the outer arbiter which adjudicates conflicts between opponents. Because of the aforementioned conflicts there is a dissipation of energy in the whole system. There are four types of flows between agents in this system: flow of energy (money) from patients to health service agents and to insurance companies; 


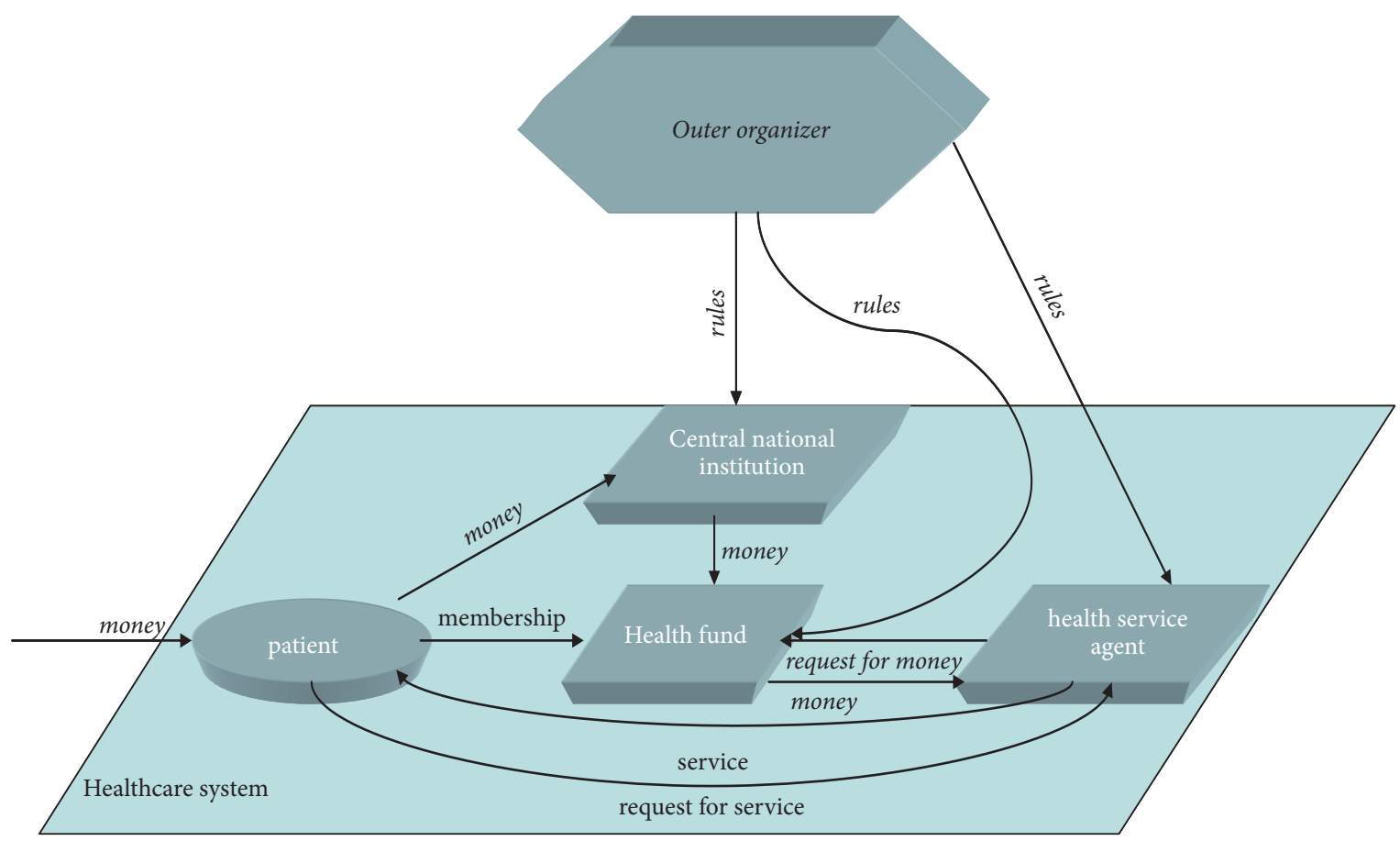

FIGURE 5: The scheme of relations between agents in the German model.

service requests from patient to health service agents and to insurance companies; flow of services from health service agents and insurance companies to the patients; and calls for arbitrations to the outer arbiter from all types of the agents, as well as rulings from the outer arbiter that become, according to American law system, the new rules for the whole healthcare system. Another drawback of the system is delays in payments from insurance companies as well as in the arbitrations. The game is a zero-sum game taken as a whole but a negative-sum game in the health service subsystem. Increasing of functional abilities of the health service part of the system demands financing the insurance companies.

\subsection{Type 3: Healthcare Costs Covered by Health Funds} (Krankenkassen): The German Model. Health service is organized according to this model in Germany. In Poland this model existed since $1^{\text {st }}$ January 1999 until the end of March 2003. Money is paid by citizens to the central national institution (Bundesversicherungsamt in Germany) and is redistributed to the health funds proportionally to the number of their members; see Figure 5.

Health funds are national institutions that play a role similar to insurance companies described above. On the one hand, health funds, as national institutions, have much greater financial resources for their disposal than private insurance companies, which, theoretically, enables financing healthcare on a much broader scope. On the other hand, however, as state institutions they are burdened with a huge and costly bureaucratic apparatus and are often entangled in political activities. As a practical monopolist in financing healthcare services, health funds in cooperation with the government arbitrarily set refunding policy, including the prices of their services. And as national institutions they enjoy immunity and justify their ineffectiveness by the lack of funds from the government. Any pathologies are justified by political and economic situations. They also often create strong lobbying groups, which, under cover of public interest and patient well-being, realize their own interests. These drawbacks are not sufficiently weakened by a limited possibility to choose the health fund by the patient. From the point of view of Mazur's theory, the system comprises an external accumulators network, in which a single accumulator is much larger than in the American model, but with much higher energy dissipation, caused by high bureaucratic burden. Selfcontrol of the subsystems in this model is limited. To sum up, there are four types of agents: patients, health service agents, health funds, and outer organizers. Neither healthcare agents nor health funds are autonomous systems but only controllable systems. Patients are autonomous systems but with very limited choice of actions. Health funds are privileged players in that they have guaranteed income according to the rules stated by the outer organizer. The patient is forced to be a member of a health fund. There is a significant energy dissipation in the system. This is caused by the flow of money first to the central institution and only then to health funds.

4.4. Type 4: The Fully Centralized Model. Health service is organized according to this model in Poland since April 2003. This is the least efficient of all the models because the nature of the system causes information loss and extreme energy dissipation, i.e., waste of the means, cybernetic energy. The system is centrally planned and controlled; see Figure 6. As a result, the expenses planned for particular services are distant from reality. They are highly underestimated, which forces 


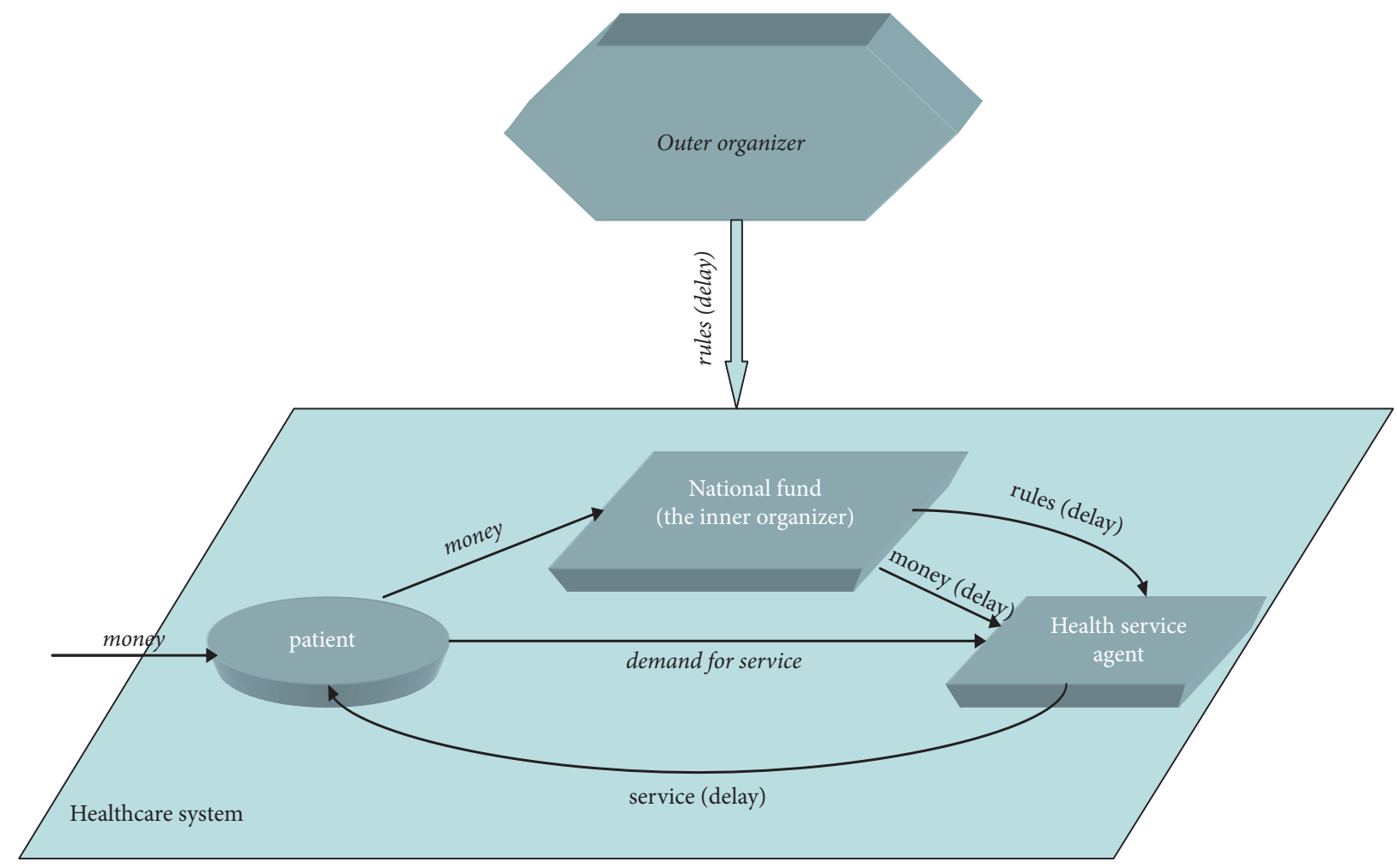

FIgURE 6: The scheme of relations between agents in the fully centralized model.

hospitals to deny execution of services in the last quarter of the year, aware that the national fund will not cover the costs. As a result, hospitals do not utilize their potential, and patients wait for diagnosis and treatment, and costly medical equipment is not used. The regulations of refunding the costs of medicine are set arbitrarily, which naturally causes pharmaceutical companies to lobby for their products. Low salaries of physicians and nurses and high salaries of the system officers are the next feature of the system, Nieszporska [26]. From the cybernetic point of view the whole healthcare system is overcontrolled.

Not only the single inner organizer, the National Health Fund, but also the outer organizer, first of all the Ministry of Health, that holds the control over the whole system, is present in the system. The inner organizer controls health service agents and the outer organizer controls both the inner organizer and the health service agents. This implies that patients, who are formally autonomous systems (organizers do not control them directly), do not have, in practice, any possibility to choose a strategy. Because of central control of the huge system there are large delays in control. Furthermore, there is not only a huge dissipation of the energy on every level of the system but also the system is extremely inefficient, the aforementioned lack of possibility of utilization of the whole potential of the health service agents. Although in the whole system there is a single huge accumulator, the National Health Fund, it is extremely dissipative and controlled in ineffective way.
4.5. Type 5: The Hypothetical Participative Healthcare System. The participated healthcare system is a proposal described in Bielecki \& Stocki [11]. Let us briefly recall the very idea of the system. In the proposed model the hospital is the primary functional unit of the healthcare system. This means that any community health centre is a part of a concrete hospital. Each hospital has a bank account for collecting the insured citizens' money: its accumulator. Financial resources would be transferred from the citizen directly to the hospital selected by the patient. Each hospital announces services offered from the minimal insurance amount and services offered for extra insurance or pay. The hospital would also be responsible for refunding medicines and defining its policy in this respect. If a patient needed a service unavailable in a hospital, the hospital would buy the service from another, specialized, hospital, which will generate the net of interacting hospitals; see Figure 7. The patient has full freedom in choosing the hospital, including the specialized ones, and makes the decision on the basis of the hospital announcements. A dissatisfied patient has the right to change the hospital and transfer the money to a different hospital. Each hospital would have the freedom to start subsidiaries such as other hospitals or community health centres any place in the country. The hospitals are independent and any subsidy by the government should be forbidden. An inefficient hospital goes bankrupt and its property is bought by other hospitals. Hospitals have full freedom of management and employment strategies. The hospital has no means to impose pressure on the patient. 


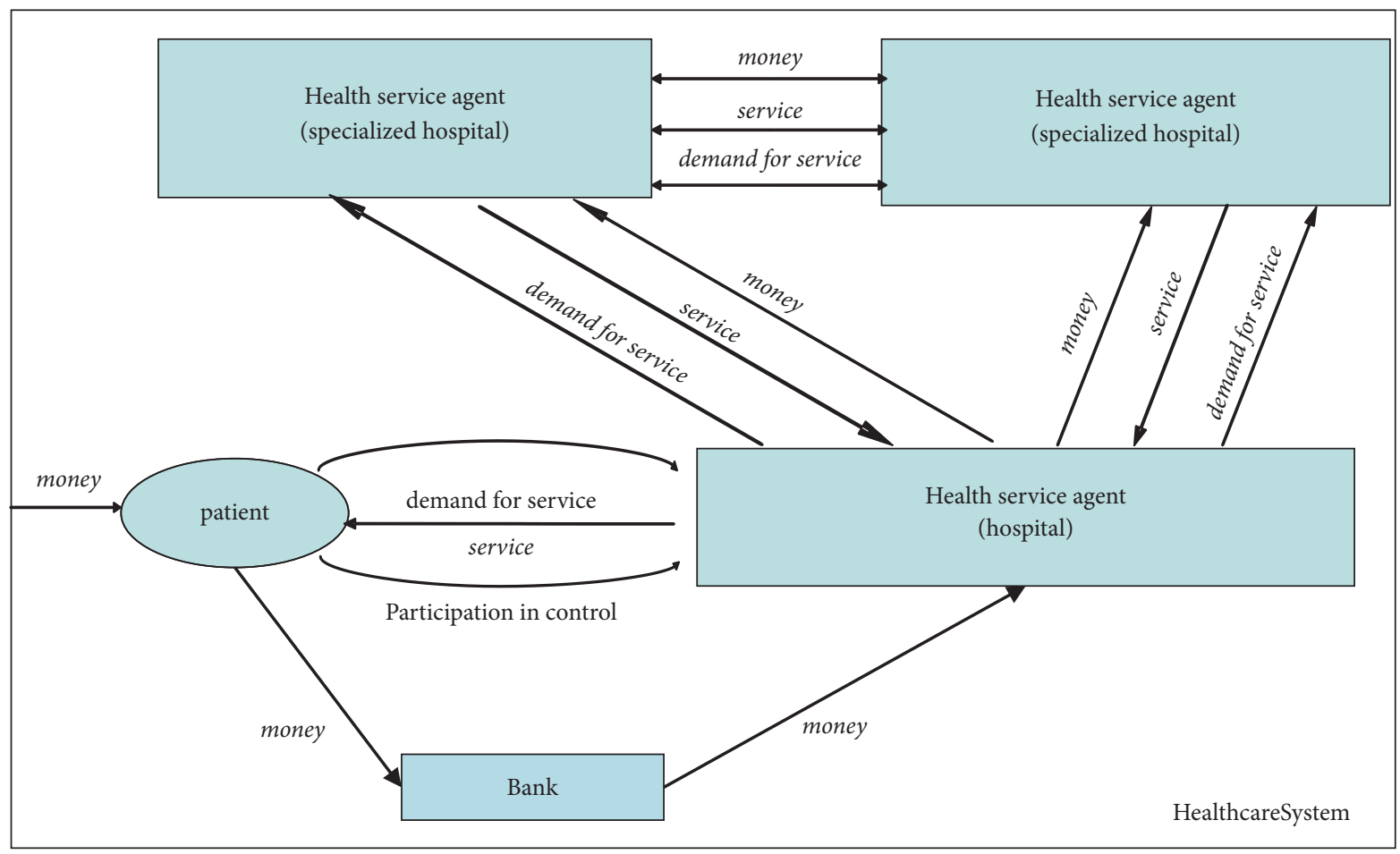

FIgURE 7: The scheme of relations between agents in the proposed participative model.

It cannot keep the patient if he wants to be under the care of another hospital. It cannot refuse insuring a patient if he has chosen a given hospital. The money transfer requires two additional changes in the function of the existing institutions: internal revenue and banks. Internal revenue would control whether a citizen paid the insurance in the amount required in the given country, and the banks would have to provide a service in which the amount paid to the hospital account by a citizen would be confidential and only the fact of payment would be visible. Confidentiality is necessary to make sure that all citizens are treated equally. The hospital knows the total amount of money at its disposal. Similarly as in the system fully paid by the patients, there are only two types of agents: patients and health service agents. Relations between them are direct, i.e., without any middle units such as funds and insurance companies and, therefore, dissipation of means in the whole system is minimal; see Figure 7.

Furthermore, all the agents are autonomous systems with maximal abilities of self-control. The whole healthcare system is autonomous as well. Furthermore, patients together with the health service agent to which they belong constitute an autonomous system as well. Thus, the whole system is hierarchical. It should also be stressed that the proposed system is the only among the considered ones in which longterm (strategic) aims of all types of agents are consonant. This implies, among others, that in this system not only the system financing is optimal and the services are provided quickly but also prevention and care of health are naturally stimulated by the system. Such activities as care of health by physical activity of patients, Bassuk et al. [27], as well as any other constructive initiatives of the patients, will be promoted by the system because such activities are profitable for all participants of the system. For instance, in the proposed system, patients can constitute groups according to their therapeutic and care interests which can improve both prevention and care. In such a way subjectivity, Bielecki \& Nieszporska [28], Hayek [29], and Wojtyła [30, 31], and commune aspects play an important role in the system as the factor of innovations. Therefore, the flow of information between patients, first of all by using the Internet, will play an important role in the system. This aspect of the system has to be worked out in detail; results obtained by del Val et al. [32] and in Chen [33] seem to be a good starting point for such research.

\section{Discussion}

As it has been mentioned at the beginning of this paper, all the existing healthcare systems suffer from numerous pathologies. It turns out that the sources of these pathologies can be analysed effectively from the cybernetic point of view, for all types of political, economic, and social conditions. Thus, the healthcare systems are analysed as systems of interacting agents that are considered in the frame of Mazur's theory. The properties of the whole system are studied from game theory point of view which is generalized in comparison with its classical form. Thus, in order to carry out the analysis, the types of agents and relations between them have to be specified. The relations consist in flowing of demands, controls such as rule specification, pieces of information, services, and matter and means (energy). Dissipation of means in the system is analysed. This dissipation depends on the degree of the game cooperativeness. If both 
TABLE 1: Summary of the cybernetic properties of the analyzed healthcare systems.

\begin{tabular}{|c|c|c|c|c|c|}
\hline & Type 1 & Type 2 & Type 3 & Type 4 & Type 5 \\
\hline Types of agents & $\begin{array}{l}\text { patients: autonomous } \\
\text { health service agents: } \\
\text { autonomous }\end{array}$ & $\begin{array}{l}\text { Patients: autonomous } \\
\text { health service agents: } \\
\text { autonomous } \\
\text { insurance companies: } \\
\text { autonomous } \\
\text { outer arbiter }\end{array}$ & $\begin{array}{l}\text { patients: autonomous } \\
\text { health service agents: } \\
\text { controllable health } \\
\text { funds: controllable } \\
\text { outer organizer }\end{array}$ & $\begin{array}{l}\text { Patients controllable } \\
\text { health service agents: } \\
\text { controllable } \\
\text { Health Fund, } \\
\text { outer organizer }\end{array}$ & $\begin{array}{l}\text { patients: autonomous } \\
\text { health service agents: } \\
\text { autonomous }\end{array}$ \\
\hline $\begin{array}{l}\text { Type of } \\
\text { the whole system }\end{array}$ & autonomous & $\begin{array}{c}\text { autonomous } \\
\text { with outer arbitration }\end{array}$ & $\begin{array}{c}\text { partially } \\
\text { controllable }\end{array}$ & $\begin{array}{c}\text { fully } \\
\text { controllable }\end{array}$ & autonomous \\
\hline Energy dissipation & zero & $\begin{array}{l}\text { minimal in the whole } \\
\text { system, } \\
\text { significant in the } \\
\text { healthcare subsystem }\end{array}$ & significant & huge & zero \\
\hline $\begin{array}{l}\text { Types of flows and } \\
\text { delays in flows }\end{array}$ & $\begin{array}{l}\text { money: no delays } \\
\text { requests: no delays } \\
\text { services: no delays }\end{array}$ & $\begin{array}{c}\text { money: in some flows } \\
\text { delays exist } \\
\text { requests: no delays } \\
\text { services: no delays } \\
\text { rulings: delays exist }\end{array}$ & $\begin{array}{l}\text { money: delays exist } \\
\text { requests: no delays } \\
\text { services: no delays } \\
\text { rules: no delays } \\
\text { controls: no delays }\end{array}$ & $\begin{array}{l}\text { money: delays exist } \\
\text { requests: no delays } \\
\text { services: delays exist } \\
\text { rules: delays exist } \\
\text { controls: delays exist }\end{array}$ & $\begin{array}{l}\text { money: no delays } \\
\text { requests: no delays } \\
\text { services (?) }\end{array}$ \\
\hline $\begin{array}{l}\text { Payoff type } \\
\text { of the game }\end{array}$ & zero-sum & $\begin{array}{l}\text { zero-sum in the whole } \\
\text { system, } \\
\text { negative sum in the } \\
\text { healthcare subsystem }\end{array}$ & negative sum & negative sum & zero-sum \\
\hline $\begin{array}{l}\text { Cooperativity } \\
\text { of the game }\end{array}$ & $\begin{array}{l}\text { Tactically: partially } \\
\text { cooperative } \\
\text { Strategically: } \\
\text { non-cooperative }\end{array}$ & $\begin{array}{c}\text { Tactically: partially } \\
\text { cooperative } \\
\text { Cooperative: in the } \\
\text { healthcare subsystem } \\
\text { Strategically: } \\
\text { non-cooperative }\end{array}$ & non-cooperative & non-cooperative & cooperative \\
\hline Privileged agents & do not exist & do not exist & health funds & $\begin{array}{c}\text { National Health } \\
\text { Fund, outer organizer }\end{array}$ & do not exist \\
\hline Accumulators & many small individual & many big & a few very big & single huge & many big \\
\hline
\end{tabular}

tactical and strategic aims of all agents are consonant then the game is fully cooperative and energy is not wasted for rivalry between agents of various types. As a consequence, the system is stable and robust, i.e., resistant to external disorders. Existence of middle agents is another source of energy dissipation. The functionality of agents and the whole system, i.e., the degree of their autonomy (in cybernetic meaning), is considered as well. The fact that agents have aims which are mutually contradictory is one of the main sources of the healthcare systems drawbacks and can be observed in all current healthcare systems. Central overcontrol on various levels of management causes other pathologies which obstruct the agents' initiative and possibility in choice of strategy. This, among others, violates patients' subjectivity. Furthermore, central overcontrol causes delays in controls, services, and means flows. The summary of the properties of the analysed healthcare systems, i.e., the main types of the existing ones and the hypothetic participative system proposed by Bielecki \& Stocki [11], is specified in Table 1. Let us use the presented approach to diagnose the pathologies which exist in the specified systems.

In the residual healthcare system (type 1) three pathologies are visible clearly. First of all, the whole system is tactically only partially cooperative, which can be the source of incorrect decisions made by patients who can overestimate the meaning of price of medical service and, as a consequence, choose the service which is cheap but is of poor quality and ineffective. Secondly, the whole system is strategically noncooperative which means that the care has interventional character; i.e., the system is focused on treatment, not on prevention. Furthermore the fact that in the whole system only small individual accumulators exist causes the fact that the healthcare is far from full functionality because possibilities of long, complex treatment are very limited. As a consequence, the system is effective in shortterm medical treatment but is far from optimal in serious cases.

In the healthcare system conjugate to insurance companies (type 2) the outer arbiter exists. This means that autonomy of the whole system is limited the more so because the arbiter is totally independent of the system. The whole system is only partially cooperative at the tactical level; service agents aspire to cure patients and patients want to be cured. Interests of insurance companies, service agents (hospitals), and patients are divergent which absorbs arbitrage and causes delays and energy dissipation. Furthermore, the whole system is noncooperative at the strategic level. The whole game is zero-sum but the health subsystem is negative-sum game 
because significant part of money is transferred to insurance companies.

The healthcare system based on health funds (type 3) is not autonomous but partially controllable. What is worse, this control is susceptible to political aspects and the whole system is organized by outer authorities. The energy dissipation is significant because of maintaining bureaucracy and, as a consequence, the whole game is a negative-sum game. Health funds are privileged agents which consume disproportionately amounts of energy. Because of the whole system structure, significant delays in energy (money first of all) flows can appear.

The centralized healthcare system (type 4) suffers from numerous deep pathologies. The system is fully controllable by an organizer, the National Health Fund, which is a privileged agent but is not interested in achieving the main superior strategic aim of the whole system, taking care of patients' health. The whole system is not cooperative and there are delays flows of energy, services, and controls as well as a huge energy dissipation. These drawbacks are significantly bigger than the ones in three types of healthcare systems discussed above and make the system so inefficient that its basic functionalities are threatened, Kolwitz [34].

To sum up, the functionality of all four discussed types of healthcare systems is far from optimal. It should be stressed that each of them suffers from crucial drawbacks. Moreover, in none of them the realization of the superior aim of the whole system activity, the effective care of citizens, is ensured. The proposed approach allows us to work out foundations of hypothetical participative healthcare system. This system, which is autonomous and consists of autonomous agents, is fully cooperative and, as a consequence, functionally optimal. It ensures realization of the superior aim of the whole system, effective healthcare. The global cooperativeness of the whole system, i.e., the fact that the aims, both tactic and strategic, of all agents are concordant, implies that the system will be focused on the care of health and prevention. In the proposed hypothetical system the dysfunctions observed in the other systems are removed. Thus, in contrast to the all other systems, the proposed system, type 5 , is fully cooperative. This means, among others, that the energy dissipation is in the system minimal. The existence of many big accumulators on the one hand allows avoiding centralization in the management of energy resources and, on the other hand, ensures stabilization of the system and access to more expensive therapies. This allows avoiding energetic problems that are present in the systems of types 1 and 4 . The proposed (type 5) system, unlike the insurance system (type 2), the system based on funds (type 3), and the centralized one (type 4), is fully autonomous and, as a consequence, is self-controllable which implies that it can compensate for adverse external influences. The absence of external arbiters and organizers as well as the system cooperativeness makes the system able to solve its problems quickly and effectively in accordance with its own interests.

The presented studies, i.e., this paper and Bielecki \& Stocki [11], are an attempt to apply strict formal methods to analyse such complex systems as healthcare systems on the national level. The proposed approach, based on autonomous systems theory, multiagent systems, and a modified game theory, differs from well-known systemic methods, which do not analyse the whole system but reduce the management of the healthcare systems to the level of microeconomics, Figueras et al. [9], or to the level of a single domains of the healthcare system, Lenaway et al. [10]. The introduced methodology allowed us to detect a few new aspects of the system such as problem of energy dissipation and storage in the system, in particular with reference to the level of cooperation in the system, the problem of delays in flows of resources, services, controls, and demands, and the problem of the whole system stability and controllability in the context of its autonomy. The existing systems are far from optimal ones and the proposed approach allows us to specify the properties of optimal system functionality. Treating the units of the healthcare system and the whole healthcare system as cybernetic systems and using the proposed agent-game theory for searching the optimal strategy in relationships between patients, physicians, and hospitals is one of the ways to change and correct existing systems. Without such studies, either only attempts of small improvements in the frame of the existing systems can be taken (Song \& Shi [35] can be put as an example) or the proposed reforms turn to be ineffective. Attempts of reforms undertaken in the USA are spectacular example of a failure, Angell [36]. As a result, the US healthcare system is so inefficient although it is highly financed. It should be stressed, however, that the presented approach requires considerations of many variables including qualitative ones. This can generate challenging problems.

It should also be mentioned that the considered problem refers to a few other topics such as introducing innovations in healthcare systems, connected strictly not only to medical practice, but also to decision support systems on various levels of medical units management, Artexe et al. [37] and Toro et al. [38]. Additionally, the studies presented in this paper are situated in the stream of research in which the game theory is used for analysis of the effectiveness of common exploitation of limited resources, Ostrom [39], Ostrom \& Gardner [40], and Anderies et al. [41]. In the case of our studies, services in the health sector are the aforementioned resources. It turns out that although classical game theory is useful for a description of a simple economic game and it generates interesting mathematical problems (Becker et al. [42, 43] and Geller et al. [44] can be put as examples), it is insufficient for analysing the complex games in which qualitative aspects of game strategies, such as the game stability, separate analysis of tactical (short-term) and strategic (long-term) aspects of a game, dissipation of energy, and functional properties of agents, have to be taken into consideration.

\section{Conclusions}

In this paper, a comprehensive and universal system of analyzing functional healthcare properties at the state level has been proposed. By treating individual entities and health service institutions as agents within the framework of the theory of autonomous systems, the proposed methodology allows the analysis of functional properties of individual 
agents. In addition, relationships and processes between individual agents are analyzed as well. The aforementioned theory of autonomous systems is supplemented by an original method of analyzing the global properties of the entire system using modified version of game theory. In this version, not only the payment table of individual participants is taken into consideration, but also the analysis of the stability of the entire game, the degree of its cooperativeness, and dissipation of energy is carried out. The proposed method allows for quick detection not only of individual dysfunctions of the whole system, but also to know their causes and, consequently, to suggest ways to remove them. The proposed approach was used to analyze the main types of existing healthcare systems and allowed indicating their dysfunctions. It also served to propose a hypothetical, optimal model for the organization of healthcare at the state level.

It should be emphasized that the proposed approach is universal and can therefore be used to analyze other complex systems, such as education system, energy system, and communication system.

\section{Conflicts of Interest}

The authors declare that they have no conflicts of interest.

\section{References}

[1] World Health Organization, "World health statistics 2014," http://apps.who.int/iris/bitstream/10665/112738/1/9789240692671_ eng.pdf?ua $=1,2016$.

[2] http://www.nfz.gov.pl/, 2016.

[3] D. J. Brenner and C. D. Elliston, "Estimated radiation on risks potentially associated with full-body CT screening," Radiology, vol. 232, no. 3, pp. 735-738, 2004.

[4] K. W. Krause, "Taking our medicine: what hope for skepticism in healthcare?” Skeptical Inquirer, vol. 37, no. 6, pp. 22-24, 2013.

[5] C. Seife, "Is drug research trustworthy?" Scientific American, vol. 307, no. 6, pp. 56-63, 2012.

[6] Y. Bar-Yam, "Improving the effectiveness of health care and public health: a multiscale complex systems analysis," American Journal of Public Health, vol. 96, no. 3, pp. 459-466, 2006.

[7] E. D. Holmboe, D. A. Fiellin, E. Cusanelli, M. Remetz, and H. M. Krumholz, "Perceptions of benefit and risk of patients undergoing first-time elective percutaneous coronary revascularization," Journal of General Internal Medicine, vol. 15, no. 9, pp. 632-637, 2000.

[8] B. J. Zikmund-Fisher, M. P. Couper, E. Singer et al., "Deficits and variations in patients' experience with making 9 common medical decisions: the decision survey," Medical Decision Making, vol. 30, pp. 85S-95S, 2010.

[9] J. Figureas, R. Robinson, and E. Jakubowski, Eds., Purchasing to Improve Health Systems Preformance, Open University Press, Maidenhead, UK, 2005.

[10] D. Lenaway, P. Halverson, S. Sotnikov, H. Tilson, L. Corso, and W. Millington, "Public health systems research: setting a national agenda," American Journal of Public Health, vol. 96, no. 3, pp. 410-413, 2006.

[11] A. Bielecki and R. Stocki, "Systems theory approach to the health care organization on national level," Cybernetics and Systems, vol. 41, no. 7, pp. 489-507, 2010.
[12] S. C. Andersen, "How to improve the outcome of state welfare services: governance in a systems-theoretical perspective," $\mathrm{Pub}$ lic Administration, vol. 83, no. 4, pp. 891-907, 2005.

[13] T. Mlakar and M. Mulej, "Complementarity of the living systems and the dialectical systems theories: The case of public medical care in Slovenia," Cybernetics and Systems, vol. 38, no. 4, pp. 381-399, 2007.

[14] E. G. Montgomery and V. Oladapo, "Talent management vulnerability in global healthcare value chains: a general systems theory perspective," Journal of Business Studies Quarterly, vol. 5, pp. 173-189, 2014.

[15] D. A. Shepherd and R. Suddaby, "Theory building: a review and integration," Journal of Management, vol. 43, no. 1, pp. 59-86, 2016.

[16] M. Mazur, Cybernetic Theory of Autonomous Systems, PWN, Warsaw, Poland, 1966.

[17] M. Mazur, Cybernetics and Character, PIW, Warsaw, Poland, 1976.

[18] A. Bielecki, "The general entity of life: a cybernetic approach," Biological Cybernetics, vol. 109, no. 3, pp. 401-419, 2015.

[19] W. B. Cannon, Wisdom of the Body, Norton, New York, NY, USA, 1932.

[20] W. R. Ashby, An Introduction to Cybernetics, Chapman \& Hall, London, UK, 1956.

[21] J. von Neumann and O. Morgenstern, Theory of Games and Economic Behavior, Princeton University Press, Princeton, NJ, USA, 1944.

[22] P. D. Straffin, Mathematical Association of America, Mathematical Association of America, Wash, USA, 1993.

[23] J. Watson, Strategy. An Introduction to Game Theory, W.W. Norton and Company, New York, NY, USA, 2002.

[24] J. Ferber, Harlow, Multi-Agent System: An Introduction to Distributed Artificial Intelligence, Ed., Addison Wesley Longman, Harlow, UK, 1999.

[25] W. Sulis, "A formal framework for collective intelligence," in Dynamics, Synergetics and Autonomous Agents, W. Tschacher and J. P. Dauwalde, Eds., vol. 8, pp. 224-237, Studies of Nonlinear Phenomena in Life Science, 1999.

[26] S. Nieszporska, "Priorities in the Polish health care system," European Journal of Health Economics, vol. 18, no. 1, pp. 1-5, 2017.

[27] S. S. Bassuk, T. S. Church, and J. E. Manson, "Why exercise works magic," Scientific American, vol. 309, no. 2, pp. 74-79, 2013.

[28] A. Bielecki and S. Nieszporska, "The proposal of philosophical basis of the health care system," Medicine, Health Care and Philosophy, vol. 20, no. 1, pp. 23-35, 2017.

[29] F. Hayek, The Constitution of Liberty, University of Chicago Press, Ill, USA, 1960.

[30] C. K. Wojtyła, "Subjectivity and the irreducible in man," Analecta Husserliana, vol. 7, pp. 107-114, 1978.

[31] K. Wojtyła, “The acting person,” in Analecta Husserliana, Reidel Publishing, Dordrecht, Holland, 1979.

[32] E. del Val, M. Rebollo, and V. Botti, "Strategies for cooperation emergence in distributed service discovery," Cybernetics and Systems, vol. 45, no. 3, pp. 222-240, 2014.

[33] L.-S. Chen, "Recognizing key service factors of attracting new virtual community members," Cybernetics and Systems, vol. 44, no. 4, pp. 305-324, 2013.

[34] M. Kolwitz, "The Polish healthcare system: perspectives and possibilities for adoption of healthcare systems from other 
countries of the European Union," Annales Academiae Medicae Stetinensis, vol. 56, no. 3, pp. 131-143, 2010 (Polish).

[35] Q. Song and K. Shi, "A fuzzy waiting time contract for patients public health care," Journal of Intelligent and Fuzzy Systems, vol. 27, pp. 1001-1009, 2014.

[36] M. Angell, "Obamacare confronts a fiscal crisis. Why the affordable care act doesn't add up," New Labor Forum, vol. 22, no. 1, pp. 44-46, 2013.

[37] A. Artetxe, E. Sanchez, C. Toro et al., "Impact of reflexive ontologies in semantic clinical decision support systems," Cybernetics and Systems, vol. 44, no. 2-3, pp. 187-203, 2013.

[38] C. Toro, E. Sanchez, E. Carrasco et al., "Using set of experience knowledge structure to extend a rule set of clinical decision support system for alzheimer's disease diagnosis," Cybernetics and Systems, vol. 43, no. 2, pp. 81-95, 2012.

[39] E. Ostrom, "Collective action and the evolution of social norms," Journal of Economic Perspectives (JEP), vol. 14, no. 3, pp. 137-158, 2000.

[40] E. Ostrom and R. Gardner, "Coping with asymmetries in the commons: self-governing irrigation systems can work," Journal of Economic Perspectives, vol. 7, no. 4, pp. 93-112, 1993.

[41] J. M. Anderies, M. A. Janssen, and E. Ostrom, "A framework to analyze the robustness of social-ecological systems from an institutional perspective," Ecology and Society, vol. 9, no. 1, 2004.

[42] R. A. Becker, S. K. Chakrabarti, W. Geller, B. Kitchens, and M. Misiurewicz, "Hyperbolic dynamics in nash maps," in Discrete Dynamics and Difference Equations, Proceedings of the Twelfth International Conference on Difference Equations and Applications, pp. 15-45, World Scientific Publishing, 2010.

[43] R. A. Becker, S. K. Chakrabarti, W. Geller, B. Kitchens, and M. Misiurewicz, "The dynamics of the Nash map for 2 by 2 games," in Dynamics, Games and Science II, vol. 2 of Springer Proceedings in Mathematics, pp. 549-565, Springer, 2011.

[44] W. Geller, B. Kitchens, and M. Misiurewicz, "Microdynamics for nash maps," Discrete and Continuous Dynamical Systems - Series A, vol. 27, no. 3, pp. 1007-1024, 2010. 


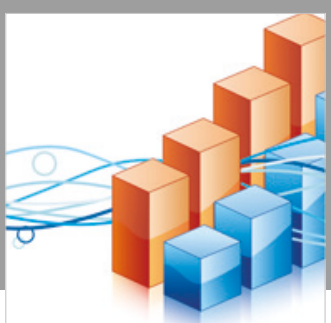

Advances in

Operations Research

\section{-n-m}
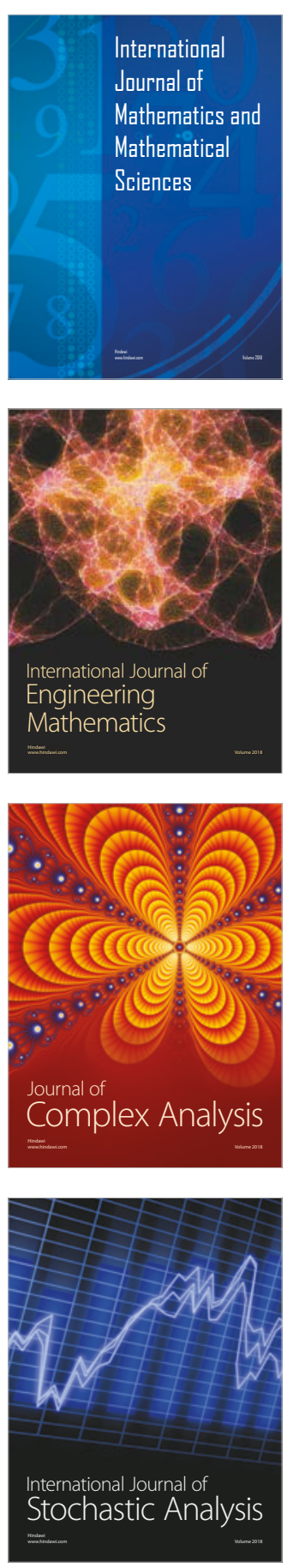
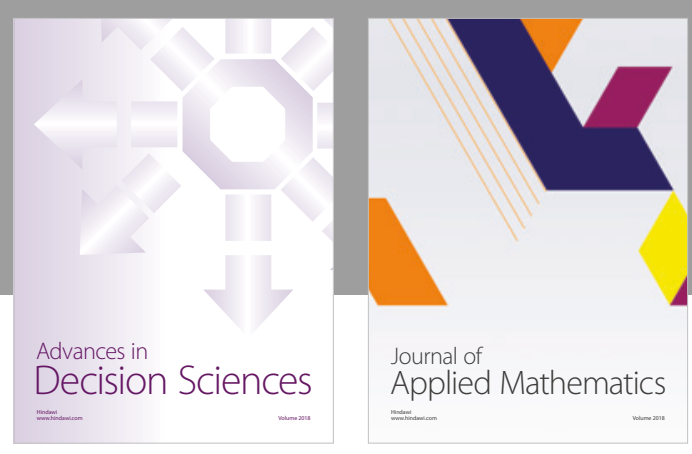

Journal of

Applied Mathematics
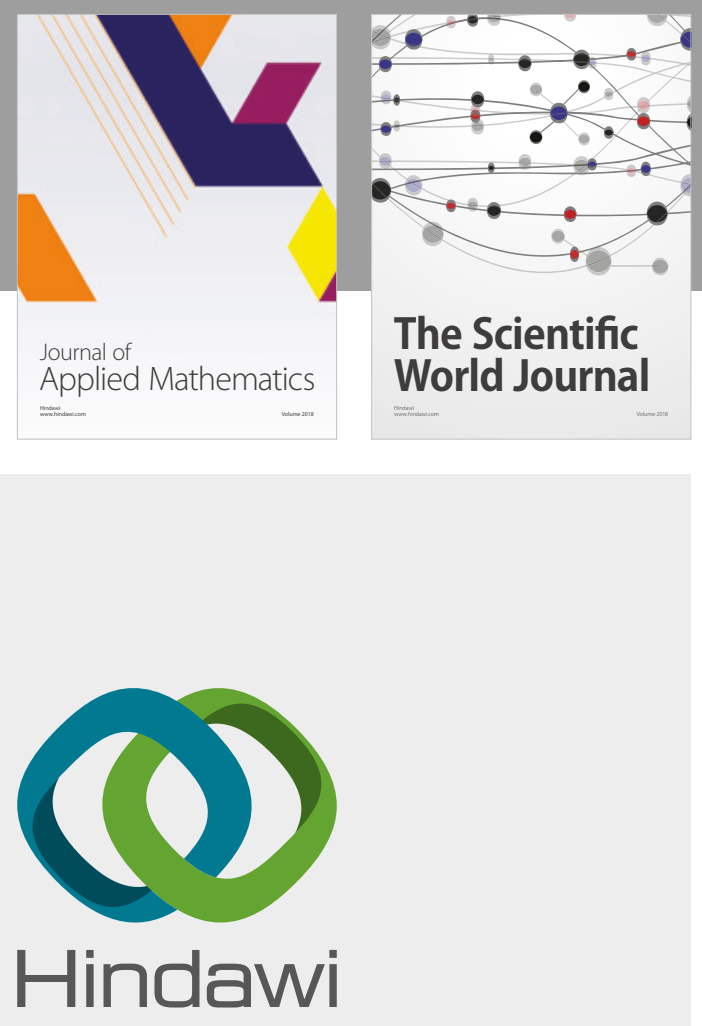

Submit your manuscripts at

www.hindawi.com

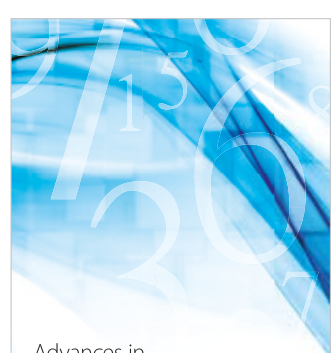

Advances in
Numerical Analysis
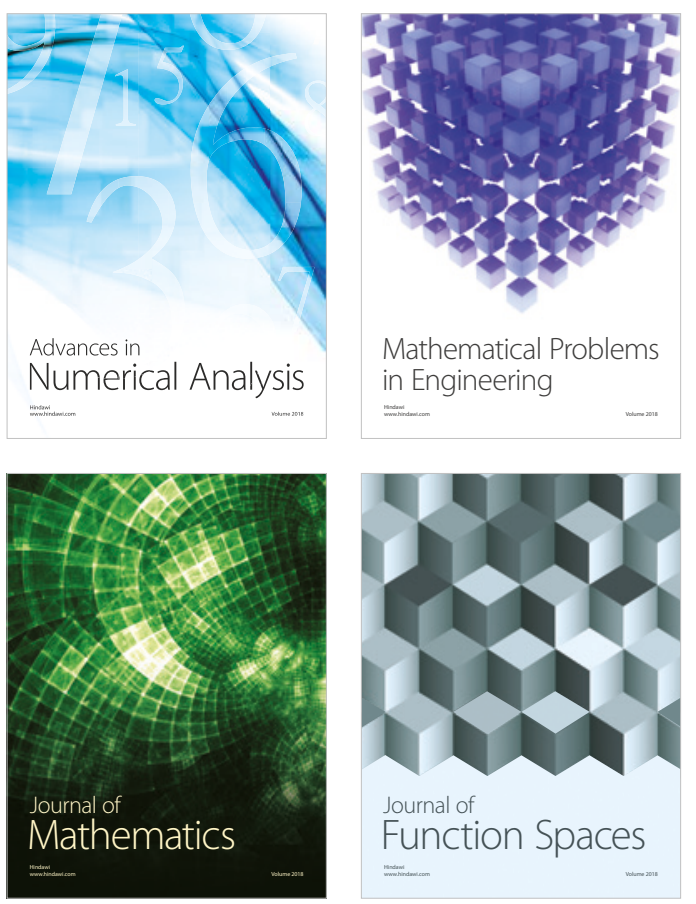

Mathematical Problems in Engineering

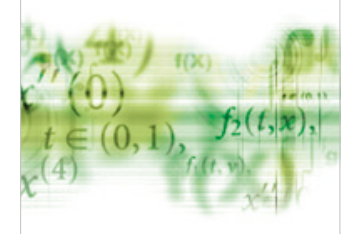

International Journal of

Differential Equations

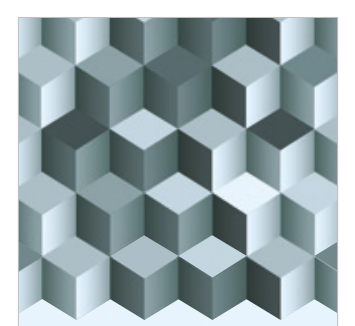

Journal of

Function Spaces
The Scientific

World Journal

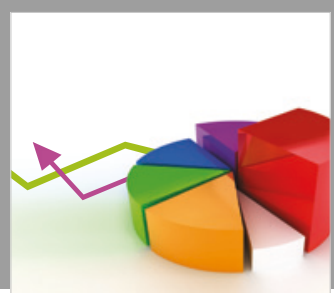

Journal of

Probability and Statistics
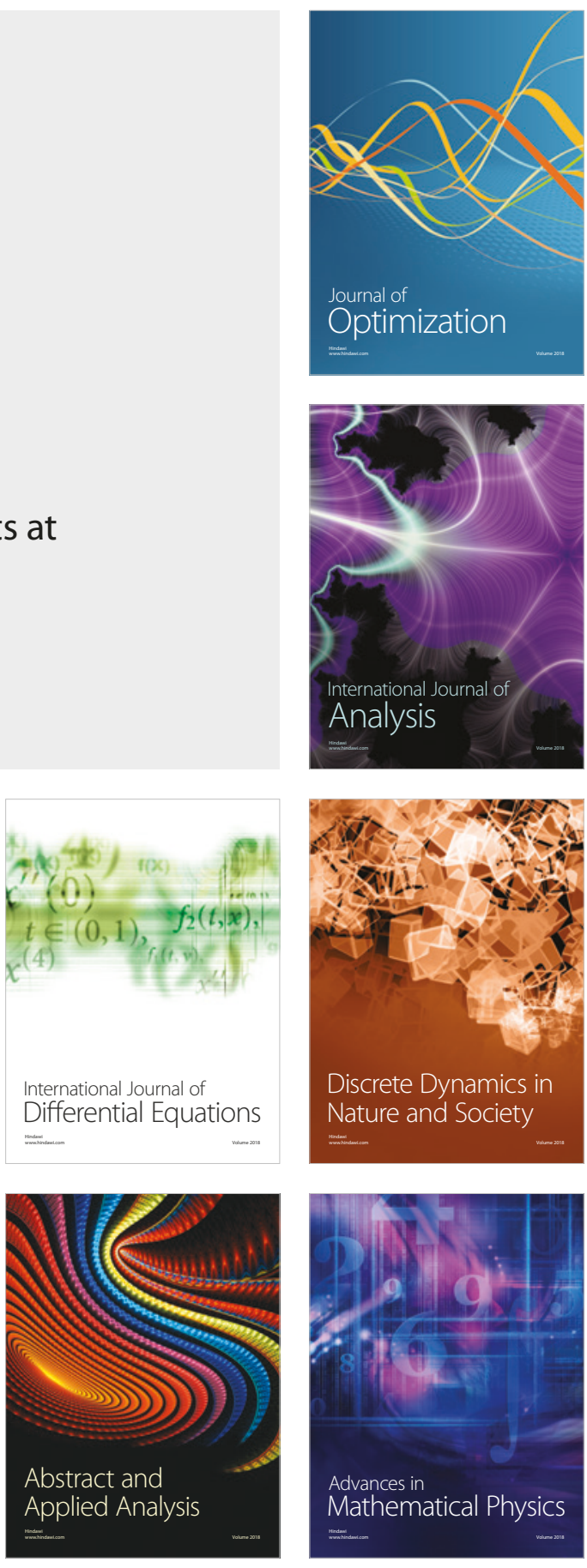